\title{
Endoscopic Surgery Without Decompressive Craniectomy in Large Putaminal Intracerebral Hemorrhage: Assessment of Efficacy and Safety
}

Yuanliang Ye ${ }^{1,2}$, Qiujing Wang ${ }^{1 *}$, Weiyang Ou ${ }^{1}$, Jian $\mathrm{He}^{1}$ and Zhenhui Zhao ${ }^{1}$

(c) 2019 The Author(s)

\begin{abstract}
Background: Decompressive craniectomy (DC) is performed conventionally for large putaminal intracerebral hemorrhage (ICH). However, DC causes local skull defect and leads to post-surgical cranioplasty. The aim of this study is to investigate the effectiveness and safety of an endoscopic procedure to treat large putaminal ICH without DC.

Methods: This retrospective study included 112 large putaminal ICH patients who underwent hematoma evacuations with either an endoscopic procedure (group A) or with DC (group B) between January 2009 and June 2017. The efficacy was evaluated by mean modified Rankin Scale (mRS) three months after surgery. Safety was evaluated by mortality rate and postoperative complications. Univariate and multivariate logistic regression analyses were performed to determine the risk factors for clinical outcomes.

Results: The study included 49 patients in group A and 63 in group B. The mRS scores in both groups were similar after 3 months' follow-up $(p=0.709)$. There was no difference in the mortality rate between the two groups $(p=0.538)$. The rate of complications was lower in group A than that in group $\mathrm{B}(p=0.024)$. Smaller preoperative midline shift $(p=0.008)$ and absent intraventricular extension $(p=0.044)$ have contributed significantly to better outcomes.
\end{abstract}

Conclusion: Endoscopic hematoma evacuation without DC is safe and effective for patients with large putaminal $\mathrm{ICH}$ and deserves further investigation, preferably in a randomized controlled setting.

Keywords: Endoscopic surgery, Intracerebral hemorrhage, Outcome, Cerebrospinal fluid drainage

\section{Introduction}

Spontaneous intracerebral hemorrhage $(\mathrm{ICH})$ is one of the most deadly forms of stroke with an extremely high mortality rate $[1,2]$. Patients with large spontaneous $\mathrm{ICH}$

\footnotetext{
*Correspondence: qiujingwang1@126.com

1 The National Key Clinical Specialty, The Engineering Technology Research Center of Ministry of Education of China, Guangdong Provincial Key Laboratory on Brain Function Repair and Regeneration, Department of Neurosurgery, Zhujiang Hospital, Southern Medical University, Guangzhou 510282, Guangdong Province, China

Full list of author information is available at the end of the article
}

This comment refers to the article available at https://doi.org/10.1007/ s12028-019-00851-z. experience poor outcomes [3-7]. Although the International Surgical Trial in Intracerebral Hemorrhage study showed that emergency surgical hematoma evacuation failed to improve the outcome of ICH patient comparing with the same type of patients who received initial medical management without surgery [8], surgical treatment of large ICH has been considered as a life-saving intervention. Currently, the prompt measure to reduce an increasing intracranial pressure (ICP) is primarily a surgical approach through either only decompressive craniectomy (DC) or DC with hematoma evacuation. However, DC could bring many delayed complications and might eventually lead to cranioplasty after surgery. 
With the rapid advancement of imaging software and transparent tube sheath, endoscopic surgery has gradually become an effective and well-accepted method for treating ICH [9-13]. Endoscopic hematoma evacuation has become well received for its high evacuation rate and less complication, especially in patients with moderatesized hematoma [14]. In the present study, we applied endoscopic surgery without DC for patients with large putaminal ICH and assessed the efficacy and safety of this procedure. We also investigated the impact of preoperative clinical factors on the surgical outcomes.

\section{Methods}

\section{Patients}

Between February 2014 and June 2017, 49 patient with large putaminal ICH received the endoscopic procedure (group A). The group A patients were matched to a group of 63 patients who were treated, between January 2009 and June 2014, with DC along with hematoma evacuation (group B). The intensive care unit, medical, and operating room practices had been kept the same during both study periods. The patients and their family members consented to accept serious neurologic deficits as a consequence of the procedures. The ICP was monitored with a cannula placed in the contralateral lateral ventricle at the end of surgery. The study was approved by the ethics committee of Zhujiang Hospital in agreement with the Declaration of Helsinki. All research was performed in accordance with relevant guidelines and regulations. Informed consent was obtained by the ethics committees. The family members signed the written surgical consent before surgery.

\section{Inclusion and Exclusion Criteria}

Patients were included or excluded in the study according to the following criteria. Inclusion criteria: (1) spontaneous ICH in putamen based on computed tomography (CT) scan; (2) the volume of the hematoma was greater than $50 \mathrm{ml}$; (3) the patients' family consented and signed the proxy for the procedure. Exclusion criteria: (1) the $\mathrm{ICH}$ was caused by trauma, tumor, moyamoya, aneurysm, or vascular malformation; (2) the patient was accompanied by severe cardiac, hepatic, renal, or pulmonary dysfunctions; (3) patients did not have a follow-up CT scan 7 days after surgery; (4) patient's family or legal representative did not consent to surgical treatment.

\section{Surgical Procedures}

In group A, a 4-cm skin incision was made on the frontal or temporal scalp of hemispheric ICH. The entry site of craniotomy was widened to 20 to $25 \mathrm{~mm}$ in diameter. Dura mater was incised and opened, and a small size incision on the cortical pia was performed. A transparent plastic sheath was inserted, with its insertion distance based on the preoperative CT scan, to the core of the hematoma. The rigid endoscope measuring $0^{\circ}$ and $4 \mathrm{~mm}$ in diameter (Karl Storz, Germany) was held in the left hand, while a suction cannula was performed in the right hand. Once the sheath was steady, the rigid endoscope and suction cannula were then introduced into the hematoma cavity through the endoscopic corridor. The hematoma was removed while the sheath was gradually withdrawn. The cerebral cortex would collapse as long as the hematoma was removed satisfactorily (Fig. 1a:IIII). For patients in group B, surgery was performed by removing a large bone flap, and then hematoma was removed via endoscope or under microscope. The size of DC was approximately 10-11 cm (anterior-posterior) by $8-9 \mathrm{~cm}$ (from temporal bone base to superior sagittal sinus). Duraplasty was implemented by using galeaperiost flap (Fig. 1b: I-III). ICP was monitored through a cannula placed in the contralateral lateral ventricle at the end of surgery.

\section{Postoperative Management}

Assessment of Glasgow Coma Scale (GCS) was executed every $2 \mathrm{~h}$ for 7 days after surgery. Brain CT scan was performed immediately after surgery and repeated every day for 7 days postoperatively. However, if the patient showed signs of deterioration, immediate brain CT scan was carried out. A lumbar catheter drain was applied after surgery in order to observe the clarification of the cerebrospinal fluid (CSF). In case of infection, patients would receive amikacin (20 $\mathrm{mg}, 1-2$ times/day) introduced into the vertebral canal. Postoperative analgesic sedation was carried out during $24 \mathrm{~h}$ after surgery. Conservative management included mannitol, glycemic control, and intensive blood pressure management. Tracheotomy was used when poor capacity of expectoration occurred. ICP monitoring was undertaken routinely in this study.

\section{Clinical and Radiological Follow-Up}

Complications, GCS, mortality, and modified Rankin Scale (mRS) were documented for 3 months after surgery. Meningitis was considered present with symptoms such as positive meningeal irritation sign, CSF leukocyte count $>1000 / \mathrm{mm}^{3}$, and positive CSF bacterial culture. Postoperative hydrocephalus, extra-axial fluid collection, and cerebral infarction were identified on postoperative CT scans. The mRS scores were defined as favorable (mRS 0-3) and unfavorable (mRS 4-6). Preand postoperative hematoma volumes were assessed by Slicer software, and the rate of hematoma evacuation was calculated as follows: Preoperative hematoma volume-postoperative hematoma volume]/preoperative hematoma volume $\times 100 \%$. Brain edema volumes at 


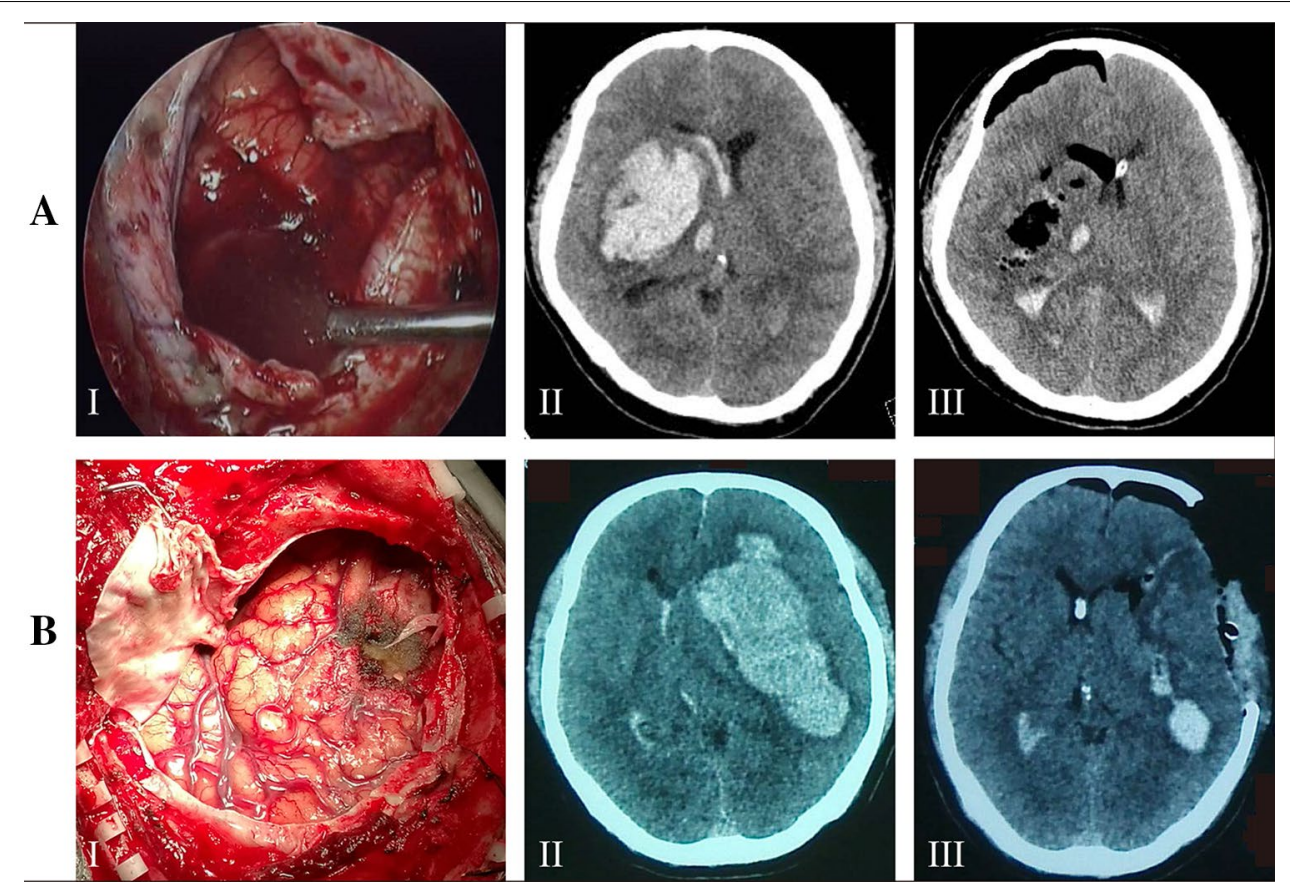

Fig. 1 a Endoscopic surgery for large putaminal ICH without DC. The brain tissue collapsed immediately after endoscopic hematoma evacuation (I). Preoperative CT shows right hemispheric large ICH (II), and postoperative CT shows well-evacuated ICH with slight edema (III). b DC with hematoma evacuation for large putaminal ICH. A large frontoparietal craniectomy is performed, and hematoma is evacuated by endoscope (I). Preoperative $\mathrm{CT}$ shows left hemispheric large ICH (II), and postoperative $\mathrm{CT}$ shows the satisfactorily evacuated ICH, large left frontoparietal craniectomy, and a cannula in right ventricles (III)

7 days postoperative were measured using semi-automatic volumetry, with a threshold-based algorithm (5-33 HU).

\section{Statistical Analysis}

All statistical analyses were performed using SPSS 22 for Windows (SPSS Inc., Chicago, Illinois). Continuous variables were expressed as mean \pm standard deviation or median with interquartile range depending on the distribution of the variables. Categorical variables were expressed in frequency or as a percentage. Pearson's Chisquare tests were used to determine any statistical difference about proportions. Continuous variables were compared using independent t-test or Mann-Whitney $U$ test. We used the logistic regression model to estimate the impact of preoperative clinical factors on the surgical outcome. The final model was adjusted on confounding factors. A $p$ value less than 0.05 was considered statistically significant.

\section{Results}

\section{Baseline Characteristics}

There were 112 patients enrolled in the study, including 69 male and 43 female. The mean age at diagnosis was $55.75 \pm 13.19$ years (range: $39-83$ years). There were
49 patients suffering from large $\mathrm{ICH}$ in group A and 63 patients in group B. There were no significant differences in preoperative GCS scores $(p=0.142), \mathrm{ICH}$ volume $(p=0.153)$, midline shift $(p=0.161)$, preoperative antiplatelet therapy $(p=0.683)$, time from onset to surgery $(p=0.133)$, and pupillary abnormalities $(p=0.126)$ in both groups. No patients in group A underwent second DC after surgery (Table 1).

\section{Evaluation of Efficacy}

The average rate of hematoma evacuation in groups $\mathrm{A}$ and B was $94.48 \%$ and $93.80 \%$, respectively. There was no statistical significance between these two groups $(p=0.725)$. There was no difference in the postoperative brain edema volume between the two groups $(p=0.382)$. After 3 months' follow-up, the mRS scores were 3.44 in group A and 3.64 in group $B$, with no statistical significance $(p=0.709)$ (Table 2 and Fig. 2).

\section{Evaluation of Safety}

The mortality rate in groups A and B was $8.16 \%(4 / 49)$ and $9.52 \%(6 / 63)$, respectively, with no statistical significance between these two groups $(p=0.538)$. Six patients experienced postoperative complications in group A with one suffered from new brain hemorrhage 
Table 1 General data of the 112 patients with large putaminal ICH

\begin{tabular}{|c|c|c|c|}
\hline Variable & $\begin{array}{l}\text { Group A (non-DC) } \\
n=49\end{array}$ & $\begin{array}{l}\text { Group B (DC) } \\
n=63\end{array}$ & $p$ Value \\
\hline Mean age, years ${ }^{\mathrm{a}}$ & $59.63 \pm 15.56$ & $53.64 \pm 11.75$ & 0.457 \\
\hline Male, no. (\%) & $31(63.27)$ & $38(60.31)$ & 0.750 \\
\hline Pre-ICH volume $(\mathrm{ml})^{\mathrm{a}}$ & $64.53 \pm 15.48$ & $66.99 \pm 5.13$ & 0.153 \\
\hline Side of hematoma, no. (\%) & & & 0.350 \\
\hline Left & $16(32.65)$ & $26(41.27)$ & \\
\hline Right & $33(67.35)$ & $37(58.73)$ & \\
\hline Pre-GCS ${ }^{b}$ & $6(5,7)$ & $5(4,6)$ & 0.142 \\
\hline Pre-midline shift, mmª & $11.42 \pm 0.29$ & $13.05 \pm 0.36$ & 0.161 \\
\hline Preoperative AP, no. (\%) & $5(10.21)$ & $8(12.70)$ & 0.683 \\
\hline Intraventricular extension, no. (\%) & & & 0.589 \\
\hline Present & $32(65.31)$ & $38(60.32)$ & \\
\hline Absent & 17(34.69) & 25(39.68) & \\
\hline Signs of cerebral herniation, no. (\%) & $37(75.51)$ & $39(61.90)$ & 0.126 \\
\hline Time from onset to surgery $(h)^{\mathrm{a}}$ & $4.82 \pm 2.25$ & $4.23 \pm 1.31$ & 0.133 \\
\hline
\end{tabular}

AP Antiplateleted patients, DC decompressive craniectomy, GCS Glasgow Coma Scale, ICH intracerebral hemorrhage

${ }^{\text {a }}$ Values are expressed as the mean $\pm \mathrm{SD}$

b Values are expressed as median (quartile)

Table 2 Comparison of effective and safe results between two groups in patients with large putaminal ICH

\begin{tabular}{|c|c|c|c|}
\hline Variable & Group A (non-DC) & Group B (DC) & $p$ Value \\
\hline Hematoma evacuation rate (\%) & $94.48 \pm 0.05$ & $93.80 \pm 0.05$ & 0.725 \\
\hline Midline shift reduction $(\mathrm{cm})^{\mathrm{a}}$ & $0.76 \pm 0.32$ & $0.80 \pm 0.22$ & 0.756 \\
\hline Brain edema $(m l)^{a}$ & $17.83 \pm 5.12$ & $20.88 \pm 9.71$ & 0.383 \\
\hline Mortality rate, no. (\%) & 8.16 & 9.52 & 0.538 \\
\hline Postoperative complication, no. (\%) & & & 0.024 \\
\hline Hydrocephalus & $2(4.08)$ & $3(4.76)$ & \\
\hline Cerebral infarction & $1(2.04)$ & $2(3.17)$ & \\
\hline Meningitis & $2(4.08)$ & $6(9.52)$ & \\
\hline New brain hemorrhage & $1(2.04)$ & $3(4.76)$ & \\
\hline Severe extra-axial fluid collection & $-0(0)$ & $5(7.94)$ & \\
\hline \multicolumn{4}{|l|}{$\mathrm{ICP}(\mathrm{mmHg})^{\mathrm{a}}$} \\
\hline ICP (at the end of surgery) & $9.00 \pm 1.32$ & $7.82 \pm 1.83$ & 0.112 \\
\hline ICP (Postoperative, at 1 wk) & $10.22 \pm 1.22$ & $9.09 \pm 1.70$ & 0.092 \\
\hline Pro-mRS(3 month) ${ }^{\mathrm{a}}$ & $3.44 \pm 1.33$ & $3.64 \pm 1.12$ & 0.709 \\
\hline
\end{tabular}

$D C$ decompressive craniectomy, ICH intracerebral hemorrhage, ICP intracranial pressure, $m R S$ modified Rankin Scale

a Values are expressed as the mean \pm SD; bold type indicates statistical significance

1 day after surgery, two from hydrocephalus, one from cerebral infarction, and two from meningitis, whereas 19 patients had postoperative complications in group B with three suffered from new brain hemorrhage after surgery, three from hydrocephalus, two from cerebral infarction, six from meningitis, and five from serious extra-axial fluid collection. The postoperative complications showed a significant difference between the two groups ( $p=0.024)$ (Table 2 and Fig. 3).

\section{Factors Associated with Clinical Outcome}

The clinical outcome was dichotomized into favorable (mRS 0-3) and unfavorable (mRS 4-6). Univariate logistic regression analyses of the preoperative clinical variables showed that smaller preoperative 


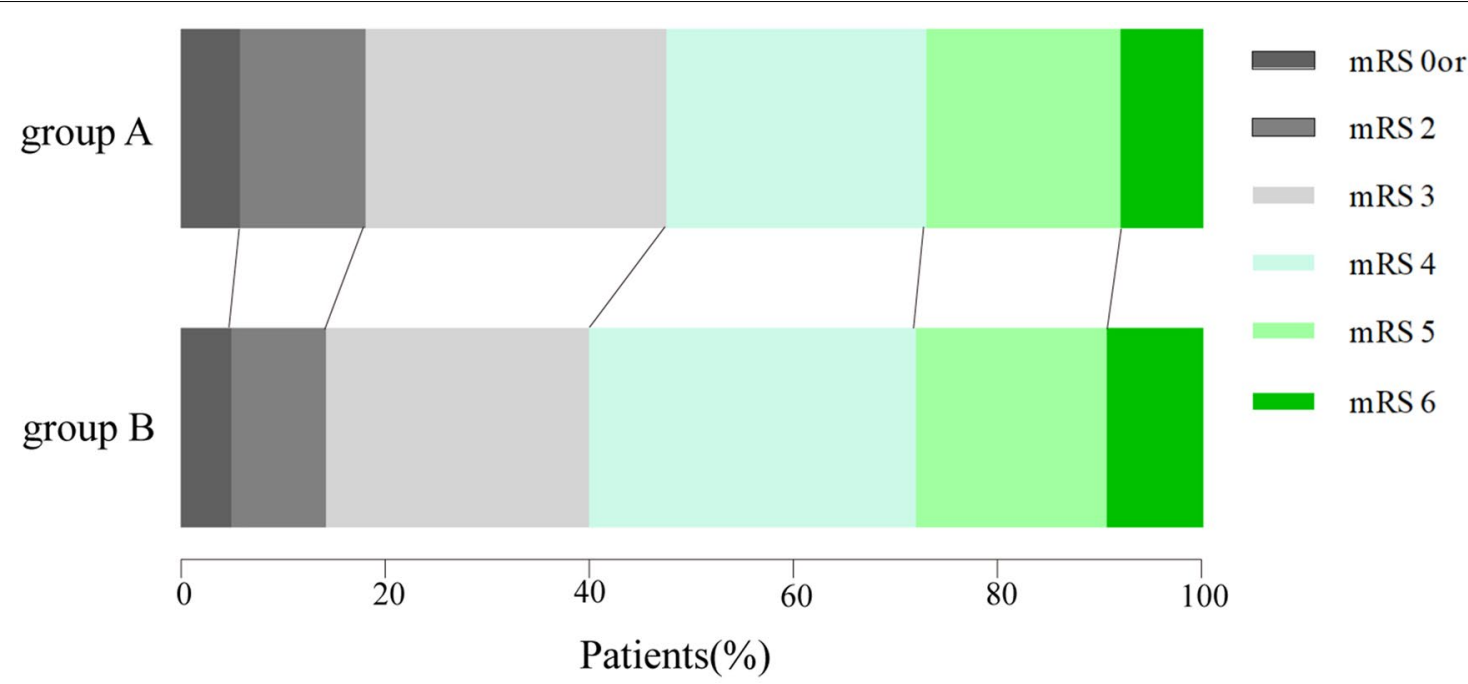

Fig. 2 Evaluation of efficacy via comparison of the mRS scores at 3 month between the two groups. Patients in group A (endoscopic hematoma evacuation) received the similar outcome compared to those in group B (DC with hematoma evacuation)

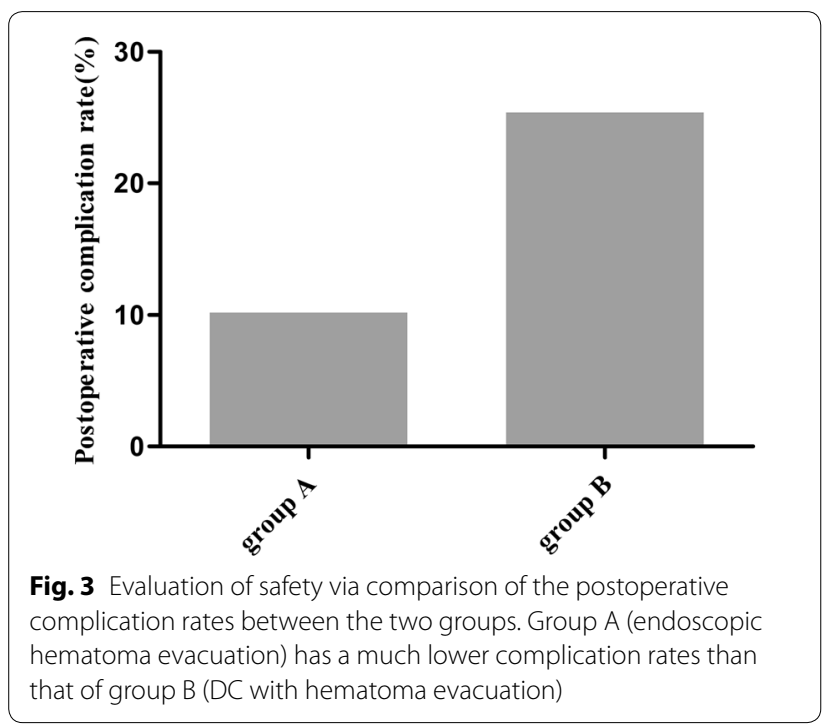

midline shift $(p=0.005)$ and absent intraventricular extension $(p=0.034)$ have significantly contributed to better outcome. However, age $p=0.272)$, sex (0.691), sides $(p=0.583)$, and pre-GCS $(p=0.147)$ were not correlated with postoperative outcomes. Multivariate logistic regression analyses of the preoperative clinical variables also showed that smaller preoperative midline shift (OR, 2.24; 95\% CI, 1.04-5.28; $p=0.044$ ) and absence of intraventricular extension (OR, 3.08; 95\% CI, 1.33$1.70 ; p=0.008)$ were associated with a favorable clinical outcome.

\section{Discussion}

In our present study, we investigated the effectiveness and safety of endoscopic surgery without DC for surgical treatment of large putaminal $\mathrm{ICH}$. We found that there was no difference in the mortality rate and the mRS score comparing the endoscopic hematoma evacuation (group A) with the DC hematoma evacuation (group B). The rate of complications was lower in endoscopic hematoma evacuation (group A) than that of the DC hematoma evacuation (group B). Smaller preoperative midline shift and absent intraventricular extension have significantly contributed to better clinical outcome. This study showed that endoscopic hematoma evacuation achieved similar clinical effect as DC hematoma evacuation.

Surgical evacuation of the intracerebral hematoma can reduce the hematoma mass, decrease ICP, improve regional blood flow, and restrict the release of toxic breakdown products by blood clot. Endoscopic surgery has been gaining popularity as a method for surgical intervention in ICH patients [15-17]. During the surgery, a transparent tube was inserted into the hematoma center, hematoma was evacuated by suction through the working space, and as the sheath was gradually withdrawn, the residual hematoma was removed. Sometimes, residual hematoma could be found by gently adjusting the sheath $[18,19]$. Moreover, due to the high pressure nature of the hematoma, its evacuation before DC was easier than after. When an intraoperative hemorrhage occurs, irrigation, compression, or coagulation were needed to secure hemostasis [20-22]. Comparing to craniotomy, endoscopic hematoma evacuation provides a high hematoma evacuation rate with minimal damage 
to normal brain tissue and lower rebleeding rate [19]. In accordance with previous study, our study also demonstrated a high hematoma evacuation rate by applying endoscopic hematoma evacuation for large $\mathrm{ICH}$ with no patients experienced postoperative bleeding.

The debate about surgical removal of large intracerebral hematoma has always focused on either hematoma evacuation or DC. The literature review about large ICH surgery is summarized in Table 3. Brain edema usually occurs after ICH evacuation, especially when the intracerebral hematomas were large [23]. Brain injury, associated brain edema, residual hematoma, and rebleeding resulted in elevation of ICP and finally lead to unsatisfactory outcome. DC can improve cerebral compliance, cerebral oxygen supply [24], and cerebral blood perfusion. As a result, it can reduce the mass effect arising from brain edema, residual hematoma, and rebleeding during the evacuation of $\mathrm{ICH}$ [25]. Therefore, some surgeons believe that it is reasonable to choose the DC procedure. However, efficient completion of hematoma evacuation without DC could also reduce the ICP and successfully manage ICP after surgery $[6,26]$. In our study, patients with endoscopic hematoma evacuation received similar mortality rate and favorite outcome compared to those with both hematoma evacuation and DC. DC may be unnecessary to treat patients with large $\mathrm{ICH}$, whereas endoscopic hematoma evacuation may present itself several advantages over DC as indicated below. First, all patients were operated via endoscopic surgery within $24 \mathrm{~h}$ of hematoma onset. The brain tissue became slack and even collapsed immediately after hematoma evacuation. Brain edema in the surgical area was acceptable. Second, residual hematoma and rebleeding were not developed with properly adjusted sheath and meticulous hemostasis. Third, by releasing CSF through the lumbar catheter drainage and dehydration treatment for postoperative brain edema, the ICP was maintained in the normal range.

CSF drainage could increase the likelihood of satisfactory outcomes after surgery. In our procedure, a cannula was placed in the contralateral lateral ventricle during surgery. The main reasons for cannula placement were to reduce ventricular blood and rapidly decompress the brainstem. The cannula was kept open to allow postoperative drainage until no further blood in the third and the fourth ventricles on $\mathrm{CT}$, and then lumbar drain was placed to promote early washout of blood in the subarachnoid space, avoiding irreversible damage to the arachnoid granulations. The main risks involved in the drainage protocols included difficulty during intraoperative ventricular puncture and postoperative intracranial infection. However, puncture based on CT measurements and strict aseptic technique could minimize these risks.

Several delayed complications of DC, including sinking flap syndrome, extra-axial fluid collection, and the development of subdural hematoma, have been reported [2730]. In addition, hydrocephalus might present in $\mathrm{ICH}$ patients treating with DC and hematoma evacuation. The reasons behind this included intraventricular extension and meningitis [31]. This study confirmed that patients operated by DC might get the high incidence of complications, including hydrocephalus. Although patients complicated with hydrocephalus did not need surgical intervention for mild ventriculomegaly and early CSF drainage, they still would undergo long-term hospitalization and slow recovery.

Table 3 Summary of the literature on surgical treatment of large ICH

\begin{tabular}{|c|c|c|c|c|}
\hline Authors and years & Study design & Surgical intervene & No. of pts & Outcome \\
\hline Murthy et al. (2005) & Retrospective & ICH evacuation with DC & 12 & $\begin{array}{l}\text { The mortality rate was } 8.3 \% \text { and } 54.5 \% \text { had } \\
\text { good functional outcome }\end{array}$ \\
\hline Takeuchi et al. (2013) & Retrospective & ICH evacuation with DC & 21 & $\begin{array}{l}\text { The mortality rate was } 10 \% \text { and } 28.6 \% \text { of } \\
\text { patients with good function }\end{array}$ \\
\hline Zhang et al. (2014) & Retrospective & $\begin{array}{l}\text { Microscopic ICH evacuation with DC and } \\
\text { CSF drainage }\end{array}$ & 33 & $\begin{array}{l}\text { The mortality rate was } 24.3 \% \text { and } 15.1 \% \text { of } \\
\text { patients with good function. }\end{array}$ \\
\hline YamaShiro et al. (2015) & Retrospective & $\begin{array}{c}\text { Endoscopic ICH evacuation without DC ver- } \\
\text { sus microscopic ICH evacuation with DC }\end{array}$ & 43 & $\begin{array}{l}\text { Endoscope without DC has similar effect in } \\
\text { terms of mortality and management of ICP } \\
\text { as compared with craniotomy }\end{array}$ \\
\hline Hadjiathanasiou et al. (2017) & Retrospective & $\begin{array}{l}\text { DC with ICH evacuation versus DC without } \\
\mathrm{ICH} \text { evacuation }\end{array}$ & 44 & $\begin{array}{l}\text { Additional ICH evacuation does not seem to } \\
\text { be beneficial }\end{array}$ \\
\hline Moussa et al. (2017) & Prospective & $\begin{array}{l}\text { ICH evacuation with DC versus ICH evacu- } \\
\text { ation }\end{array}$ & 40 & $\begin{array}{l}\text { DC with hematoma evacuation improved the } \\
\text { outcome }\end{array}$ \\
\hline Present study & Prospective & $\begin{array}{l}\text { Endoscopic ICH evacuation without DC ver- } \\
\text { sus DC with endoscopic ICH evacuation }\end{array}$ & 112 & $\begin{array}{l}\text { Pure endoscope without DC has similar effect } \\
\text { in terms of mortality and favor clinical out- } \\
\text { come as compared with craniotomy }\end{array}$ \\
\hline
\end{tabular}

CSF cerebrospinal fluid, DC decompressive craniectomy, ICH intracerebral hemorrhage, ICP intracranial pressure 
The major strength of this study is to provide an alternative surgical method to neurosurgeons. Patients with large putaminal $\mathrm{ICH}$ may not need to experience cranioplasty and thus avoided second operation and extra economic burden. The present study has some limitations. First, despite the lack of significant differences in $\mathrm{ICH}$ size, intraventricular hematomas (IVH) size, GCS, and age, these factors may have some influences on the findings because of the small size of the population studied. Second, this is a retrospective analysis without taking microsurgery in comparison. In addition, randomization was not stratified in this study when we divided patient into different groups.

\section{Conclusions}

Our findings indicate that endoscopic hematoma evacuation without DC is safe and effective for large putaminal intracerebral hematoma patients and DC may be unnecessary for rescuing these patients. Multicenter, prospective, randomized, controlled clinical trials are warranted to support our results.

\section{Author details \\ ${ }^{1}$ The National Key Clinical Specialty, The Engineering Technology Research Center of Ministry of Education of China, Guangdong Provincial Key Labora- tory on Brain Function Repair and Regeneration, Department of Neurosur- gery, Zhujiang Hospital, Southern Medical University, Guangzhou 510282, Guangdong Province, China. ${ }^{2}$ Department of Neurosurgery, Liuzhou General Hospital, Liuzhou 545001, Guangxi Autonomous Region, China.}

\section{Author Contributions}

QJ Wang and YL Ye helped in conception and design. YL Ye, WY Ou, J He, and ZH Zhao contributed to acquisition of data. YL Ye helped in the analysis and interpretation of data. YL Ye drafted the article. All authors helped in critically revising the article and in reviewing the submitted version of manuscript. QJ Wang on behalf of all authors approved the final version of the manuscript. YL Ye helped in statistical analysis. QJ Wang contributed to study supervision.

\section{Source of support}

This study received funding from the Science and Technology Project Foundation of Guangdong Province (Grant No. 2015A030313259) and Key Project of Clinical Research of Southern Medical University (Grant No. LC2016PY59).

\section{Conflicts of interest}

The authors declare that they have no conflicts of interest.

\section{Ethical approval/Informed consent}

The study was approved by the ethics committee of Zhujiang Hospital, Southern Medical University. Informed consent was obtained by the ethics committees. The family members signed the written surgical consent before surgery.

\section{Open Access}

This article is distributed under the terms of the Creative Commons Attribution 4.0 International License (http://creativecommons.org/licenses/by/4.0/), which permits unrestricted use, distribution, and reproduction in any medium, provided you give appropriate credit to the original author(s) and the source, provide a link to the Creative Commons license, and indicate if changes were made.

\section{Publisher's Note}

Springer Nature remains neutral with regard to jurisdictional claims in published maps and institutional affiliations.
Published online: 16 December 2019

\section{References}

1. Feigin VL, Lawes CM, Bennett DA, Barker-Collo SL, Parag V. Worldwide stroke incidence and early case fatality reported in 56 population-based studies: a systematic review. Lancet Neurol. 2009:8:355-69.

2. van Asch CJ, Luitse MJ, Rinkel GJ, van der Tweel I, Algra A, Klijn CJ. Incidence, case fatality, and functional outcome of intracerebral haemorrhage over time, according to age, sex, and ethnic origin: a systematic review and meta-analysis. Lancet Neurol. 2010;9:167-76.

3. Hadjiathanasiou A, Schuss P, Ilic I, Borger V, Vatter H, Guresir E. Decompressive craniectomy for intracerebral haematoma: the influence of additional haematoma evacuation. Neurosurg Rev. 2018;41:649-54.

4. Maira G, Anile C, Colosimo C, Rossi GF. Surgical treatment of primary supratentorial intracerebral hemorrhage in stuporous and comatose patients. Neurol Res. 2002;24:54-60.

5. Ramnarayan R, Anto D, Anilkumar TV, Nayar R. Decompressive hemicraniectomy in large putaminal hematomas: an Indian experience. J Stroke Cerebrovasc Dis Offic J Natl Stroke Assoc. 2009;18:1-10.

6. Yamashiro S, Hitoshi Y, Yoshida A, Kuratsu J. Effectiveness of endoscopic surgery for comatose patients with large supratentorial intracerebral hemorrhages. Neurol Med Chir. 2015;55:819-23.

7. Zhang HT, Xue S, Li PJ, Fu YB, Xu RX. Treatment of huge hypertensive putaminal hemorrhage by surgery and cerebrospinal fluid drainage. Clin Neurol Neurosurg. 2013;115:1602-8.

8. Hemphill JC 3rd, Greenberg SM, Anderson CS, et al. Guidelines for the management of spontaneous intracerebral hemorrhage: a guideline for healthcare professionals from the American Heart Association/American Stroke Association. Stroke. 2015;46:2032-60.

9. Chen CC, Chung HC, Liu CL, Lee HC, Cho DY. A newly developed endoscopic sheath for the removal of large putaminal hematomas. J Clin Neurosci Offic J Neurosurg Soc Australas. 2009;16:1338-41.

10. Miller CM, Vespa P, Saver JL, et al. Image-guided endoscopic evacuation of spontaneous intracerebral hemorrhage. Surg Neurol. 2008;69:441-6 (discussion 6)

11. Nishihara T, Teraoka A, Morita A, Ueki K, Takai K, Kirino T. A transparent sheath for endoscopic surgery and its application in surgical evacuation of spontaneous intracerebral hematomas. Technical note. J Neurosurg. 2000;92:1053-5.

12. Orakcioglu B, Beynon C, Bosel J, Stock C, Unterberg AW. Minimally invasive endoscopic surgery for treatment of spontaneous intracerebral hematomas: a single-center analysis. Neurocrit Care. 2014;21:407-16.

13. Orakcioglu B, Uozumi Y, Unterberg A. Endoscopic intra-hematomal evacuation of intracerebral hematomas — a suitable technique for patients with coagulopathies. Acta Neurochir Suppl. 2011;112:3-8.

14. Sun GC, Chen XL, Hou YZ, et al. Image-guided endoscopic surgery for spontaneous supratentorial intracerebral hematoma. J Neurosurg. 2017;127:537-42

15. Angileri FF, Esposito F, Priola SM, et al. Fully endoscopic freehand evacuation of spontaneous supratentorial intraparenchymal hemorrhage. World Neurosurg. 2016;94:268-72.

16. Wang WH, Hung YC, Hsu SP, et al. Endoscopic hematoma evacuation in patients with spontaneous supratentorial intracerebral hemorrhage. J Chin Med Assoc JCMA. 2015;78:101-7.

17. Yokosuka K, Uno M, Matsumura K, et al. Endoscopic hematoma evacuation for acute and subacute subdural hematoma in elderly patients. J Neurosurg. 2015;123:1065-9.

18. Yokosuka K, Uno M, Hirano K, Toi H, Matsuzaki K, Matsubara S. Freehand technique for putaminal hemorrhage-technical note. Neurol Med Chir. 2011;51:543-6.

19. Kuo LT, Chen CM, Li CH, et al. Early endoscope-assisted hematoma evacuation in patients with supratentorial intracerebral hemorrhage: case selection, surgical technique, and long-term results. Neurosurg Focus. 2011;30:E9.

20. Liu L, Liu X, Zhang F, et al. Dual-channel minimally invasive endoscopic port for evacuation of deep-seated spontaneous intracerebral hemorrhage with obstructive hydrocephalus. World Neurosurg. 2016;91:452-9. 
21. Nagasaka T, Inao S, Ikeda H, Tsugeno M, Okamoto T. Inflation-deflation method for endoscopic evacuation of intracerebral haematoma. Acta Neurochir (Wien). 2008;150:685-90 (discussion 90).

22. Nagasaka T, Tsugeno M, Ikeda $\mathrm{H}$, et al. Balanced irrigation-suction technique with a multifunctional suction cannula and its application for intraoperative hemorrhage in endoscopic evacuation of intracerebral hematomas: technical note. Neurosurgery. 2009;65:E826-7 (discussion

\section{E7)}

23. Gebel JM Jr, Jauch EC, Brott TG, et al. Natural history of perihematomal edema in patients with hyperacute spontaneous intracerebral hemorrhage. Stroke. 2002;33:2631-5

24. Lubillo ST, Parrilla DM, Blanco J, et al. Prognostic value of changes in brain tissue oxygen pressure before and after decompressive craniectomy following severe traumatic brain injury. J Neurosurg. 2018;128:1538-46.

25. Takeuchi S, Takasato Y, Masaoka H, et al. Decompressive craniectomy with hematoma evacuation for large hemispheric hypertensive intracerebral hemorrhage. Acta Neurochir Suppl. 2013;118:277-9.

26. Shimamura N, Munakata A, Naraoka M, Nakano T, Ohkuma H. Decompressive hemi-craniectomy is not necessary to rescue supratentorial hypertensive intracerebral hemorrhage patients: consecutive singlecenter experience. Acta Neurochir Suppl. 2011;111:415-9.

27. Akins PT, Guppy KH. Sinking skin flaps, paradoxical herniation, and external brain tamponade: a review of decompressive craniectomy management. Neurocrit Care. 2008;9:269-76.

28. Bakshi A, Bakshi A, Banerji AK. Neuroendoscope-assisted evacuation of large intracerebral hematomas: introduction of a new, minimally invasive technique. Preliminary report. Neurosurg Focus. 2004;16:e9.

29. Ban SP, Son YJ, Yang HJ, Chung YS, Lee SH, Han DH. Analysis of complications following decompressive craniectomy for traumatic brain injury. J Korean Neurosurg Soc. 2010;48:244-50.

30. Yang XF, Wen L, Shen F, et al. Surgical complications secondary to decompressive craniectomy in patients with a head injury: a series of 108 consecutive cases. Acta Neurochir (Wien). 2008;150:1241-7 (discussion 8).

31. Takeuchi S, Nawashiro H, Wada K, et al. Ventriculomegaly after decompressive craniectomy with hematoma evacuation for large hemispheric hypertensive intracerebral hemorrhage. Clin Neurol Neurosurg. 2013;115:317-22. 